This is the post-print version of an article published by W.B. Saunders Co. in Metabolism, Clinical and Experimental. The published version can be found at http://dx.doi.org/10.1016/j.metabol.2010.01.010.

Miles MP, CM Depner, RD Kirwan, and SJ Frederickson. Influence of macronutrient intake and anthropometric characteristics on plasma insulin after eccentric exercise. Metabolism, Clinical and Experimental, 59:1456-1464, 2010.

\title{
Influence of macronutrient intake and anthropometric characteristics on plasma insulin after eccentric exercise
}

\author{
Mary P. Miles, Chris M. Depner, Rochelle D. Kiwan, Sara J. Frederickson; \\ Department of Health and Human Development, Montana State University, Box 173540, Bozeman, MT 59717, USA
}

\begin{abstract}
To increase understanding of the interaction between macronutrients and insulin resistance (IR), this study sought to determine the influence of macronutrient intake and anthropometric differences on IR and inflammation responses to eccentric resistance exercise. Men and women $(n=12,19-36$ years old) participated in a crossover study and completed 6 sets of 10 unilateral maximal eccentric contractions of the elbow flexors and extensors followed by controlled diet conditions for the first 8 hours postexercise of carbohydrate/fat/protein proportions of either $75 \% / 15 \% / 10 \%$ (CHO) or $6 \% / 70 \% / 24 \%$ (FAT/PRO). Fasting glucose, insulin, homeostatic model assessment (HOMA) variables, and interleukin (IL)-1 $\beta$ were measured preexercise and 23 hours postexercise (additional measures of glucose and insulin 1 hour after meals consumed 0.5, 3, and 7 hours postexercise). Insulin increased more ( $\mathrm{P} \mathrm{b} .01)$ in the $\mathrm{CHO}$ compared with the FAT/PRO condition at 1.5, 4, and 8 hours postexercise. Insulin, HOMA-IR, and HOMA- $\beta$-cell function increased 23 hours postexercise in both conditions, whereas IL-1 $\beta$ increased 23 hours postexercise only in the $\mathrm{CHO}$ condition. Magnitude of change $(\Delta)$ for these variables associated positively with body mass index (BMI) and waist to hip ratio (WHR) in the $\mathrm{CHO}$ and inversely in the FAT/PRO condition; that is, $r=0.53$ $(P=.10)$ and $r=-0.82(P<.01)$ for BMI vs $\Delta$ insulin in $C H O$ and FAT/PRO conditions, respectively. The $\Delta$ IL-1 $1 \beta$ associated with BMI $(r=0.62, \mathrm{P}<.05)$ and WHR $(r=0.84, \mathrm{P}<.01)$ in the CHO condition. The CHO enhanced IR and inflammation as $\mathrm{BMI}$ and WHR increased, whereas fat and protein enhanced IR as BMI and WHR decreased. Thus, BMI and WHR may need to be taken into account in the development of nutritional strategies to prevent IR.
\end{abstract}

\section{Introduction}

The interaction between macronutrient consumption and the inflammatory environment within the body has great relevance to health and disease. Tissues, such as the liver, muscle, and adipose, develop insulin resistance when exposed to inflammation [1-3]. Pancreatic $\beta$-cells increase secretion of insulin to compensate for this resistance; but over time, this overcompensation cannot be maintained, and type 2 diabetes mellitus (T2DM) will occur [4]. Given the rapid rise in T2DM incidence and the lowering of the age of onset for this disease, effective intervention strategies are needed. Although clinical tests using hyperglycemic and hyperlipidemic conditions have demonstrated the potential for glucose and lipids to influence inflammation [5-11], the influence of the macronutrient composition of ingested food is not clear. This is surprising given that inflammatory cytokines such as tumor necrosis factor (TNF) $-\alpha$ and interleukin (IL)- $1 \beta$ have the capacity to increase insulin resistance $[2,12]$. A greater understanding of proinflammatory effects of nutrients is vital to the development of disease prevention strategies.

Carbohydrates, fat, and protein are the major macronutrient constituents of the diet and, thus, have a potentially large influence on the inflammatory environment within the body. High glucose conditions elicit expression of a wide array of proinflammatory genes in monocytes, including TNF- $\alpha$ and IL- $1 \beta$ [13]. There is a proinflammatory effect of hyperglycemia in obese but not normal-weight individuals $[8,9]$. Conversely, mimicking the very high free fatty acid concentrations $\left(\sim 2900 \mu \mathrm{mol} \mathrm{L}^{-1}\right)$ that occur during sepsis via intralipid and heparin infusion also stimulates inflammation and insulin resistance $[5,6]$. However, the concentrations of fatty acids achieved with intralipid/heparin infusion 
is several-fold higher than typically expected under normal circumstances in healthy or even insulin-resistant individuals ( 200-1000 $\left.\mu \mathrm{mol} \mathrm{L}^{-1}\right)[11,14]$.

Obesity and greater levels of visceral adipose tissue (AT), estimated in many studies using the waist to hip ratio (WHR), are anthropometric characteristics that influence macronutrient metabolism and promote inflammation $[15,16]$. For example, free fatty acids released from visceral AT go through the portal circulation to the liver where they alter glucose and lipid metabolism; and inflammatory mediators from visceral AT promote gluconeogenesis, dyslipidemia, and insulin resistance. Although a persistent, low-level inflammation is a characteristic of obesity, researchers have identified that a central distribution of fat mass adds to inflammation $[10,16]$. In addition, obesity and central adiposity positively both associate with insulin resistance and risk for T2DM [16]. Little is known about the influence of anthropometric characteristics in nonobese individuals, but there is evidence that visceral AT enhances hyperglycemia-induced inflammation in nonobese individuals [10]. Thus, it is likely that the series of potentially synergistic events leading to T2DM begins to occur in nonobese individuals; and examining metabolic and inflammatory shifts that occur as body mass index (BMI) and WHR increase across a nonobese population may provide insights into insulin resistance prevention strategies.

The purpose of this investigation was to determine whether (1) macronutrient intake and (2) anthropometric characteristics influence inflammation and components of the homeostatic model assessment of insulin resistance (HOMA-IR) after eccentric exercise in a nonobese population. Eccentric exercise involves forcing muscles to lengthen against resistance and has been used as a research model to induce both inflammation and a transient increase in insulin resistance $[3,17,18]$. The mechanism of this insulin resistance includes disruption of the classic insulin signaling pathway by TNF- $\alpha$ [19]; thus, this model is useful for studying the interaction of macronutrient intake with inflammation and insulin resistance in a nonobese population. We hypothesized that a high carbohydrate intake would enhance both inflammation and variables related to insulin resistance after eccentric exercise and that this effect was likely to be more pronounced in individuals with greater BMI or WHR.

\section{Methods}

\subsection{Participants}

Fourteen participants enrolled in the investigation, and 2 did not complete the study because of illness unrelated to the study. The remaining 12 participants were 19 to 36 years of age $($ male $=7$, female $=5$ ). Participants were non-weight trained and did not do any heavy lifting or lowering with the arms that resulted in soreness of the arms in the 6 months before the study. The goal of these criteria was to eliminate the possible effects of the repeated bout effect where muscle that has been exposed to eccentric contractions will have a protective adaptation that will result in decreased muscle damage with subsequent bouts of eccentric exercise for up to several months [20]. Individuals were excluded if they had a known history or condition of anemia, musculoskeletal limitations, inflammatory conditions, diabetes mellitus, heart disease, known kidney problems (excluding kidney stones), smoking, alcohol use (regardless of the amount of alcohol per drink) greater than 1 drink per day for women and 2 drinks per day for men, binge drinking ( $>4$ drinks on any 1 occasion), chronic use of anti-inflammatory medications, use of lipid-lowering medications, use of oral contraceptives, regular physical activity that results in bruising or muscle soreness, and pregnancy. All participants were informed of the risks and discomforts associated with participation and signed an informed consent document approved by the Montana State University Human Subjects Committee before participation.

\subsection{Research design}

The research design was a crossover protocol in which each participant completed a high-carbohydrate $(\mathrm{CHO})$ and a high-fat/protein (FAT/PRO) condition. The order of conditions was counterbalanced among participants and separated by 3 to 6 weeks within each participant to allow variables to return to baseline between conditions. On the first morning of each condition, participants came to the laboratory at 7:00 AM after an overnight fast and sat for 10 to 15 minutes before a resting blood sample was collected; and height, weight, and WHR were measured. Participants then performed unilateral high-force eccentric exercise to induce inflammation and consumed either a high-glycemic index CHO-based or low-glycemic index FAT/PRO-based diet for the first 8 hours postexercise. Each diet consisted of 3 meals at $0.5,3$, and 7 hours postexercise. The contralateral limb was used in the second condition. Blood was collected preexercise and at $1.5,4,8,23$, and 120 hours postexercise for measurement of TNF- $\alpha$, IL- $1 \beta$, IL-6, soluble (s) gp130 (an IL-6 receptor and antagonist), C-reactive protein (CRP), glucose, insulin, and serum creatine kinase activity $(\mathrm{CK}$, measured at preexercise and at 23 and 120 hours postexercise).

To minimize variability, participants were required to adhere to several restrictions during the time of assessment. To obtain optimal baseline assessment of blood, participants were required to be on an 8-hour fast and keep physical activity to a minimum the first morning of each condition. During the assessment period, participants were required to refrain from strenuous physical activity and physical activity that lasted longer than 60 minutes in duration. To reduce the influence of illness on inflammatory factors, participants were only tested if they had been free from known infection for at least 1 week before testing. 


\subsection{Eccentric exercise and maximal force production}

A computer-controlled isokinetic dynamometer (Kin Com 125E+; Chattecx, Chattanooga, TN) was used to perform the high-force eccentric exercise. The elbow flexor and extensor muscles of 1 arm were exercised for each condition. The point of rotation in the dynamometer was aligned with the axis of rotation in the elbow. The height of the dynamometer was adjusted so that the torso and upper arm made an angle of 0.79 radians $\left(90^{\circ}\right)$ and the upper arm was parallel with the floor. The dynamometer was connected to the arm just below the wrist via a padded support and Velcro strap.

Participants started with their elbow in a flexed position at an approximate elbow angle of 0.79 radians $\left(90^{\circ}\right)$. Afterward, the dynamometer moved their elbow to a fully extended position. The participants were instructed to maximally resist the movement of the elbow being extended by attempting to keep the elbow in a fully flexed position. From the fully extended position, the dynamometer then moved their elbow to a fully flexed position. The participants also attempted to maximally resist this movement. Although the participants were encouraged to give a maximal effort, their level of effort was subjective. The movement of the elbow from flexed to extended and back to flexed consisted of 1 repetition. The angular velocity of the dynamometer was set at 0.79 radians per second. There was a 10 -second pause in between each repetition. There were 10 repetitions per set, with a total of 6 sets. There was a 5-minute rest period between sets.

Maximal isometric strength was measured preexercise, immediately postexercise, and 24 hours postexercise. The dynamometer was adjusted for each participant the same way it was adjusted during the high-force eccentric exercise. To test maximal isometric strength, the dynamometer was set so that the elbow was at an angle of 1.57 radians $\left(90^{\circ}\right)$. The dynamometer was locked in that position, and the participants were instructed to flex or extend their elbow with maximal effort for 3 seconds. For each measure of maximal isometric strength, the participants performed this procedure 3 times; and the average of the 3 trials was used as the maximal isometric strength for that specific time. There was a 30 -second rest period in between the 3 trials for each measure of maximal isometric strength.

\subsection{Diet composition}

In each condition, meals were provided to the participants $0.5,3$, and 7 hours postexercise. The high-CHO diet consisted of corn flakes, $2 \%$ fat milk, apple juice, and Clif Bars (75\% CHO, 8.5\% fat, $16.5 \%$ protein; Clif Bar, Berkeley, CA). The macronutrient composition of this diet was $75 \%$ carbohydrate, $15 \%$ fat, and $10 \%$ protein, with each participant ingesting $1.45 \mathrm{~g}$ carbohydrate per kilogram body weight. The high-fat/protein diet consisted of turkey, cheese, and peanuts. The macronutrient composition of this diet was $6 \%$ carbohydrate, $70 \%$ fat, and $24 \%$ protein, with each participant ingesting $0.11 \mathrm{~g}$ carbohydrate per kilogram body weight. Both diets contained a total of $32.4 \mathrm{~kJ}(7.7 \mathrm{kcal})$ per kilogram of body weight at each meal, for example, $1943 \mathrm{~kJ}$ (464 kcal) at each meal for an individual weighing $60 \mathrm{~kg}$.

\subsection{Blood analysis}

Blood was collected using a standard venipuncture technique at preexercise and at 1.5, 4, 8, 23, and 120 hours postexercise. Blood was collected from an antecubital vein into chilled evacuated tubes without additive for analysis of glucose, CRP, and CK and tubes containing EDTA for TNF$\alpha$, IL-6, sgp130, IL-1 $\beta$, and insulin. The serum tubes were allowed to clot at room temperature, and the EDTA tube remained on ice until centrifugation within 30 minutes of collection. Serum and plasma were separated from cells using a refrigerated 21000R Marathon centrifuge (Fisher Scientific, Pittsburgh, PA). Samples were stored at $-80^{\circ} \mathrm{C}$ until analysis.

Serum high-sensitivity CRP (MP Biomedicals, Irvine, CA), plasma high-sensitivity TNF- $\alpha$ (R\&D Systems, Minneapolis, MN), plasma high-sensitivity IL-6 (R\&D Systems), sgp130 (R\&D Systems), and plasma highsensitivity IL-1 $\beta$ (R\&D Systems) concentrations were measured using commercially available enzyme-linked immunosorbent assay kits according to the instructions of the manufacturers. Absorbance of 96-well plates was read at the primary wavelength and corrected for secondary wavelength interference using a $\mu$ Quant Universal microplate spectrophotometer (Bio-Tek Instruments, Winooski, VT). All samples were run in duplicate. All samples for a given participant were run on the same assay plate. Manufacturer-reported detection limits for the cytokine assays were $0.1 \mathrm{mg} \cdot \mathrm{L}^{-1}, 0.106 \mathrm{pg} \cdot \mathrm{mL}^{-1}, 0.039 \mathrm{pg}$. $\mathrm{mL}^{-1}$, and $0.057 \mathrm{pg} \cdot \mathrm{mL}^{-1}$ for CRP, TNF- $\alpha$, IL-6, and IL$1 \beta$, respectively. Intraassay coefficients of variation were $13.8 \%, 16.2 \%, 9.7 \%, 8.2 \%$, and $5.0 \%$ for CRP, TNF- $\alpha$, IL- 6 , IL-1 $\beta$, and insulin, respectively.

Enzymatic assays were used to measure serum CK and plasma glucose concentrations. Serum CK activity was measured with an ultraviolet kinetic assay using a creatine kinase $N$-acetyl-L-cysteine reagent at $37^{\circ} \mathrm{C}$ in which $\mathrm{CK}$ activity is proportional to the change in NADH production and the increase in absorbance at $340 \mathrm{~nm}$ (CK-NAC reagent; Thermo Fisher Scientific, Waltham, MA). Serum glucose concentration was assayed using a glucose hexokinase reagent set in which glucose is converted to glucose-6phosphate and then to 6-phosphogluconate with the reduction of NAD+ to NADH (Pointe Scientific, Canton, $\mathrm{MI})$. The absorbance of $\mathrm{NADH}$ at $340 \mathrm{~nm}$ is directly proportional to the concentration of glucose in the sample and calculated relative to a known standard. These assays were modified for microplate analysis and read using a $\mu$ Quant Universal microplate spectrophotometer (Bio-Tek Instruments). Samples were run in duplicate. All samples for a given subject were analyzed in the same run of the assay. 
Intraassay coefficients of variation were $3.1 \%$ and $7.8 \%$ for CK and glucose, respectively.

Fasting plasma insulin and glucose concentrations were used to calculate homeostatic model assessment of $\beta$-cell function (HOMA-\%B), insulin resistance (HOMA-IR), and insulin sensitivity (HOMA-\%S). Calculations were made using the HOMA2 model calculator from www.OCDEM.ox. ac.uk [21].

\subsection{Statistics}

Data were analyzed using Statistical Program for Social Sciences (SPSS) for Windows (version 15.0.1; SPSS, Chicago, IL). Independent $t$ tests were used to determine whether sex differences were present for BMI and WHR. To compare conditions over time, a 2-way repeated-measures analysis of variance was used. All variables were normally distributed, as determined using the Kolmogorov-Smirnov test. If there were significant main effects or interactions found, paired $t$ tests analyses with the Bonferroni correction to $\alpha$ were run to determine the location of the significant differences. Bivariate Pearson product-moment correlations were used to assess associations. Statistical significance was set at the $\alpha=.05$ level.

\section{Results}

\subsection{Participant characteristics}

Six participants completed the $\mathrm{CHO}$ condition, first and 6 participants completed the FAT/PRO condition first. Body mass ranged from 54.4 to $88.9 \mathrm{~kg}$ with a mean of $72.7 \pm 9.7$ $\mathrm{kg}$. Body mass index was $23.23 \pm 3.21$ and $24.03 \pm 2.60 \mathrm{~kg}$. $\mathrm{m}^{-2}$ for women and men, respectively, with no difference $(P=.65)$ between sexes. Similarly, WHR was $0.83 \pm 0.08$ and $0.87 \pm 0.08$ for women and men, respectively, with no difference $(P=.34)$ between sexes.

\subsection{Strength loss and serum $C K$}

Loss of strength postexercise was compared between conditions to determine whether this indirect indication of muscle damage was influenced by the dietary conditions. The postexercise decrease in strength indicative of fatigue during the exercise bout was similar between conditions; however, the prolonged strength loss indicative of muscle damage was greater 24 hours postexercise in the $\mathrm{CHO}$ condition (Table 1). Serum CK activity did not increase and was similar between conditions (Table 1).

\subsection{Glucose, insulin, and HOMA variables}

One participant had very high fasting insulin (104 units, $>5$ SD from the mean, reassay yielded same value) at 23 hours postexercise in the carbohydrate conditions that was consistent with potentially not being in a fasted state. Thus, this participant was excluded from relevant analyses. Blood glucose and insulin responses after meals were consistent
Table 1

Strength loss and serum $\mathrm{CK}$ activity between $\mathrm{CHO}$ and FAT/PRO conditions

\begin{tabular}{lcc}
\hline & $\begin{array}{l}\text { CHO condition } \\
(\text { mean } \pm \mathrm{SD})\end{array}$ & $\begin{array}{l}\text { FAT/PRO condition } \\
(\text { mean } \pm \mathrm{SD})\end{array}$ \\
\hline Biceps strength loss $(\%)$ & & \\
0 h postexercise & $-13.3 \pm 12.5$ & $-14.0 \pm 11.5$ \\
24 h postexercise & $-22.7 \pm 17.6$ & $-8.0 \pm 20.5^{*}$ \\
Triceps strength loss $(\%)$ & $-1.7 \pm 20.1$ & $-6.9 \pm 31.5$ \\
0 h postexercise & $-14.1 \pm 25.2$ & $1.7 \pm 34.6$ \\
24 h postexercise & & \\
Serum CK activity $\left(\mathrm{IU} \cdot \mathrm{L}^{-1}\right)$ & $280 \pm 241$ & $191 \pm 103$ \\
Preexercise & $243 \pm 205$ & $179 \pm 120$ \\
120 h postexercise &
\end{tabular}

* $P \leq .05$ compared with $\mathrm{CHO}$ condition.

with normal glucose tolerance status for the participants and for the differing diet conditions. Plasma glucose levels decreased below fasting levels 1 hour after the 0.5 -hour postexercise meal and had returned to fasting levels 1 hour after the 3- and 7-hour postexercise meals (Fig. 1A). Plasma insulin was increased above the fasting level 1 hour after each of the 3 postexercise meals and was higher in the $\mathrm{CHO}$ compared with FAT/PRO condition at all time points except 24 hours postexercise (Fig. 1B).

Insulin and the corresponding HOMA-IR increased 23 hours postexercise in both conditions, whereas HOMA- $\% \mathrm{~B}$ increased in the FAT/PRO condition only (Fig. 1B and Table 2). The HOMA- $\% \mathrm{~S}$ did not change in either group. Blood glucose concentrations were similar between groups and conditions at preexercise and 23 hours postexercise measurements (Fig. 1A). There were no differences between conditions.

\subsection{Inflammation variables}

Evidence of postexercise inflammation was found in the $\mathrm{CHO}$ but not FAT/PRO condition. Interleukin- $\beta$ increased 23 hours postexercise in $\mathrm{CHO}$ but not FAT/PRO condition, and there was a trend $(P=.07)$ for IL-6 to be higher in the CHO compared with FAT/PRO condition (Table 2). There were no changes over time or differences between conditions for CRP, sgp130, or TNF- $\alpha$.

\subsection{Relationship among anthropometric variables and the magnitude of postexercise changes}

To determine the influence of BMI and central adiposity on the changes in inflammation and insulin resistance, we measured correlations among these variables and the magnitude of the change preexercise to 23 hours postexercise $(\Delta)$ for the variables in which changes were measured including insulin, HOMA-IR, HOMA- $\%$ B, and IL- $1 \beta$ (Table 3). Although both BMI and WHR correlated, the correlations were stronger between BMI and $\Delta$ insulin, $\Delta$ HOMA-IR, and $\Delta$ HOMA- $\% \mathrm{~B}$, indicating that BMI accounts for more of the variability in these insulin-related changes than did WHR. Conversely, WHR accounted for more of the 


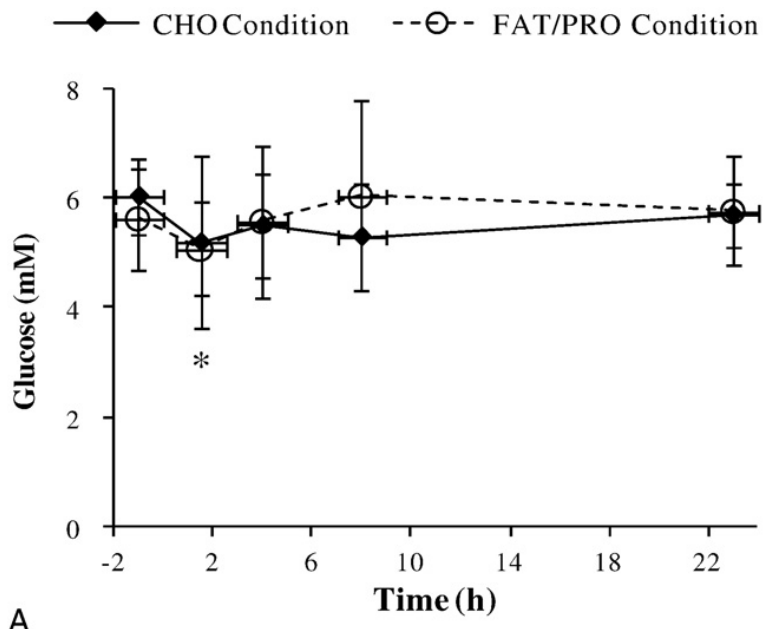

$$
\text { A }
$$

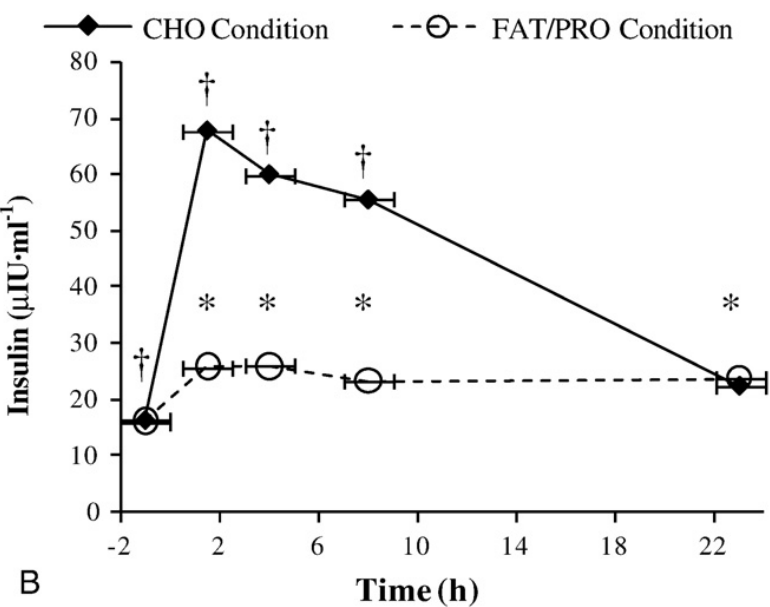

Fig. 1. Plasma glucose (A) and insulin (B) concentrations for the $\mathrm{CHO}$ and FAT/PRO conditions. $* P<.05$ of both conditions compared with preexercise; ${ }^{\dagger} P<.05$ compared with FAT/PRO condition.

variability in $\Delta \mathrm{IL}-1 \beta$ in the $\mathrm{CHO}$ condition. The divergent influence of $\mathrm{CHO}$ and FAT/PRO diets depending on BMI is illustrated for $\Delta$ insulin in Fig. 2 (A and B); that depending on WHR is illustrated for $\Delta$ IL- $1 \beta$ in Fig. 3 (A and B).

\section{Discussion}

The key finding of this study is that the increase in plasma insulin 1 day after eccentric exercise was influenced both by macronutrient intake after the exercise and by anthropometric characteristics of the participants. The exercise stimulus to induce inflammation and insulin resistance in the present study was intended to be relevant to low-level inflammation and disease risk. The eccentric exercise used a small muscle mass, resulted in a relatively small loss in strength, and did not increase serum CK. Thus, the exercise stress was low and within the realm of experience for physically inactive individuals at risk for
Table 2

HOMA estimates and inflammation variables between CHO and FAT/PRO conditions

\begin{tabular}{|c|c|c|c|}
\hline & $\begin{array}{l}\text { CHO condition } \\
(\text { mean } \pm \mathrm{SD})\end{array}$ & $\begin{array}{l}\mathrm{FAT} / \mathrm{PRO} \\
\text { condition } \\
(\text { mean } \pm \mathrm{SD})\end{array}$ & $\begin{array}{l}\text { Condition } \\
\text { Time } \\
\text { Cond } \times \text { time }\end{array}$ \\
\hline \multicolumn{4}{|c|}{ HOMA-IR (relative units) } \\
\hline Preexercise & $2.67 \pm 1.08$ & $2.15 \pm 1.03$ & $\begin{array}{l}P=.034 \\
P=.016\end{array}$ \\
\hline $\begin{array}{c}23 \mathrm{~h} \text { postexercise } \\
\beta \text {-Cell function }(\%)\end{array}$ & $3.03 \pm 1.50^{*}$ & $2.44 \pm 1.06^{*}$ & $P=.876$ \\
\hline Preexercise & $130.2 \pm 49.2$ & $128.6 \pm 55.5$ & $\begin{array}{l}P=.007 \\
P=.001\end{array}$ \\
\hline \multicolumn{4}{|c|}{ Insulin sensitivity $(\%)$} \\
\hline Preexercise & $41.4 \pm 20.7$ & $56.1 \pm 22.9$ & $\begin{array}{l}P=.008 \\
P=.831\end{array}$ \\
\hline $\begin{array}{c}23 \mathrm{~h} \text { postexercise } \\
\text { TNF- } \alpha\left(\mathrm{pg} \cdot \mathrm{mL}^{-1}\right)\end{array}$ & $43.7 \pm 26.3$ & $52.2 \pm 32.0$ & $P=.563$ \\
\hline Preexercise & $1.86 \pm 0.97$ & $2.24 \pm 1.32$ & $\begin{array}{l}P=.147 \\
P=.734\end{array}$ \\
\hline $\begin{array}{l}23 \mathrm{~h} \text { postexercise } \\
\mathrm{Il}-1 \beta\left(\mathrm{pg} \cdot \mathrm{mL}^{-1}\right)\end{array}$ & $2.10 \pm 1.10$ & $2.06 \pm 1.22$ & $P=.094$ \\
\hline Preexercise & $0.19 \pm 0.14$ & $0.21 \pm 0.18$ & $\begin{array}{l}P=.160 \\
P=.262\end{array}$ \\
\hline $\begin{array}{l}23 \mathrm{~h} \text { postexercise } \\
\mathrm{Il}-6\left(\mathrm{pg} \cdot \mathrm{mL}^{-1}\right)\end{array}$ & $0.26 \pm 0.15^{*}$ & $0.18 \pm 0.13^{\dagger}$ & $P=.043$ \\
\hline Preexercise & $1.81 \pm 1.29$ & $1.44 \pm 0.86$ & $\begin{array}{l}P=.070 \\
P=.882\end{array}$ \\
\hline $\begin{array}{c}23 \mathrm{~h} \text { postexercise } \\
\operatorname{sgp} 130\left(\mathrm{pg} \cdot \mathrm{mL}^{-1}\right)\end{array}$ & $1.95 \pm 1.57$ & $1.26 \pm 0.72$ & $P=.528$ \\
\hline Preexercise & $206.0 \pm 40.3$ & $219.0 \pm 33.6$ & $\begin{array}{l}P=.660 \\
P=.375\end{array}$ \\
\hline $\begin{array}{l}23 \mathrm{~h} \text { postexercise } \\
\mathrm{CRP}\left(\mathrm{mg} \cdot \mathrm{L}^{-1}\right)\end{array}$ & $225.6 \pm 47.4$ & $220.6 \pm 44.0$ & $P=.304$ \\
\hline Preexercise & $1.81 \pm 3.14$ & $1.60 \pm 2.75$ & $\begin{array}{l}P=.928 \\
P=.167\end{array}$ \\
\hline $23 \mathrm{~h}$ postexercise & $1.14 \pm 1.50$ & $1.19 \pm 1.66$ & $P=.627$ \\
\hline
\end{tabular}

* $P \leq .05$ compared with preexercise.

${ }^{\dagger} P \leq .05$ compared with $\mathrm{CHO}$ condition.

developing insulin resistance. Nevertheless, the combined stress of eccentric exercise and macronutrient extremes was sufficient to elicit changes in inflammation and insulin resistance variables that associated with BMI and WHR in a nonobese group of research participants. Consistent with our research hypothesis, the increase in inflammation, specifically IL- $1 \beta$, occurred only in the $\mathrm{CHO}$ condition and

Table 3

Correlations between BMI or WHR and the magnitude of change in HOMA in inflammation variables

\begin{tabular}{lrrrrrr}
\hline & \multicolumn{2}{c}{ BMI } & & \multicolumn{2}{c}{ WHR } \\
\cline { 2 - 3 } \cline { 5 - 6 } \cline { 5 - 6 } & CHO & FAT/PRO & & CHO & FAT/PRO \\
\hline$\Delta$ Insulin $\left(\mu \mathrm{IU} \cdot \mathrm{mL}^{-1}\right)$ & 0.53 & $-0.82^{\dagger}$ & & 0.54 & $-0.76^{\dagger}$ \\
$\Delta \beta$-Cell function $(\%)$ & -0.42 & $-0.79^{\dagger}$ & & -0.44 & $-0.75^{\dagger}$ \\
$\Delta$ Insulin sensitivity $(\%)$ & -0.41 & $0.62^{*}$ & & -0.39 & $0.61^{*}$ \\
$\Delta$ IR (relative units) & 0.56 & $-0.84^{\dagger}$ & & 0.58 & $-0.78^{\dagger}$ \\
$\Delta$ IL-1 $\beta\left(\mathrm{pg} \cdot \mathrm{mL}^{-1}\right)$ & $0.62^{*}$ & -0.54 & & $0.84^{\dagger}$ & -0.43
\end{tabular}

$* P \leq .05$.

$\dagger P<.01$. 
associated positively with BMI and WHR. However, the change in IL- $1 \beta$ was small; and there was no change in TNF- $\alpha$, IL-6, sgp130, or CRP 23 hours postexercise. Therefore, evidence of inflammation was limited. Associations between BMI and WHR with changes in insulin resistance variables were positive, but not strong enough to be significant. Surprisingly, increases in plasma insulin concentration, HOMA-IR, and HOMA-\%B both occurred in the absence of measurable inflammation and associated negatively with BMI and WHR in the FAT/PRO condition. This is the first study that we know of to demonstrate the potential for the same macronutrient composition of the diet to have opposing effects on insulin levels depending on BMI or WHR. This may be an important consideration in the development of T2DM prevention strategies.
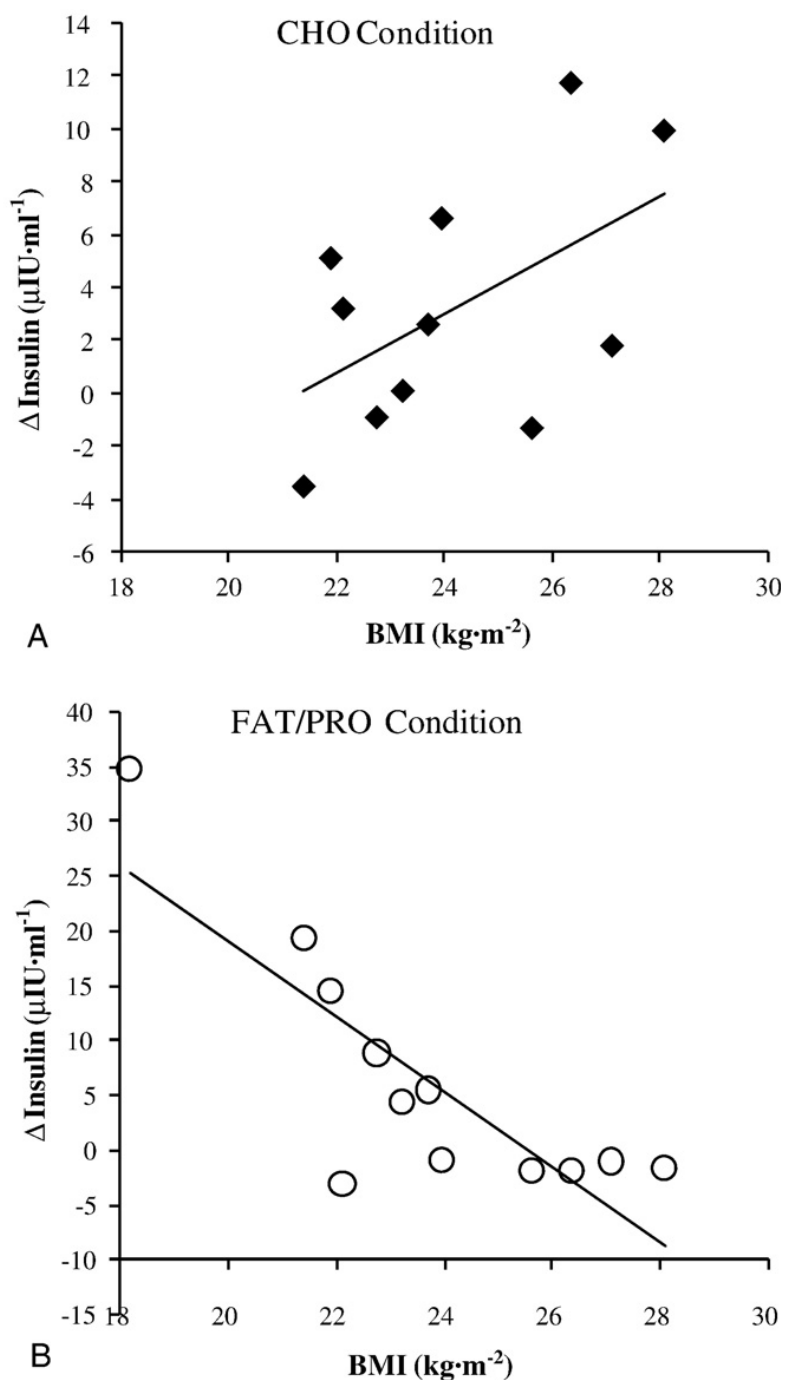

Fig. 2. Association of BMI with the change $(\Delta)$ in plasma insulin concentrations in the $\mathrm{CHO}(\mathrm{A})$ and $\mathrm{FAT} / \mathrm{PRO}$ (B) conditions. Pearson product-moment correlations were $0.53(P>.05)$ and $-0.82(P<.05)$ in the $\mathrm{CHO}$ and FAT/PRO conditions, respectively.
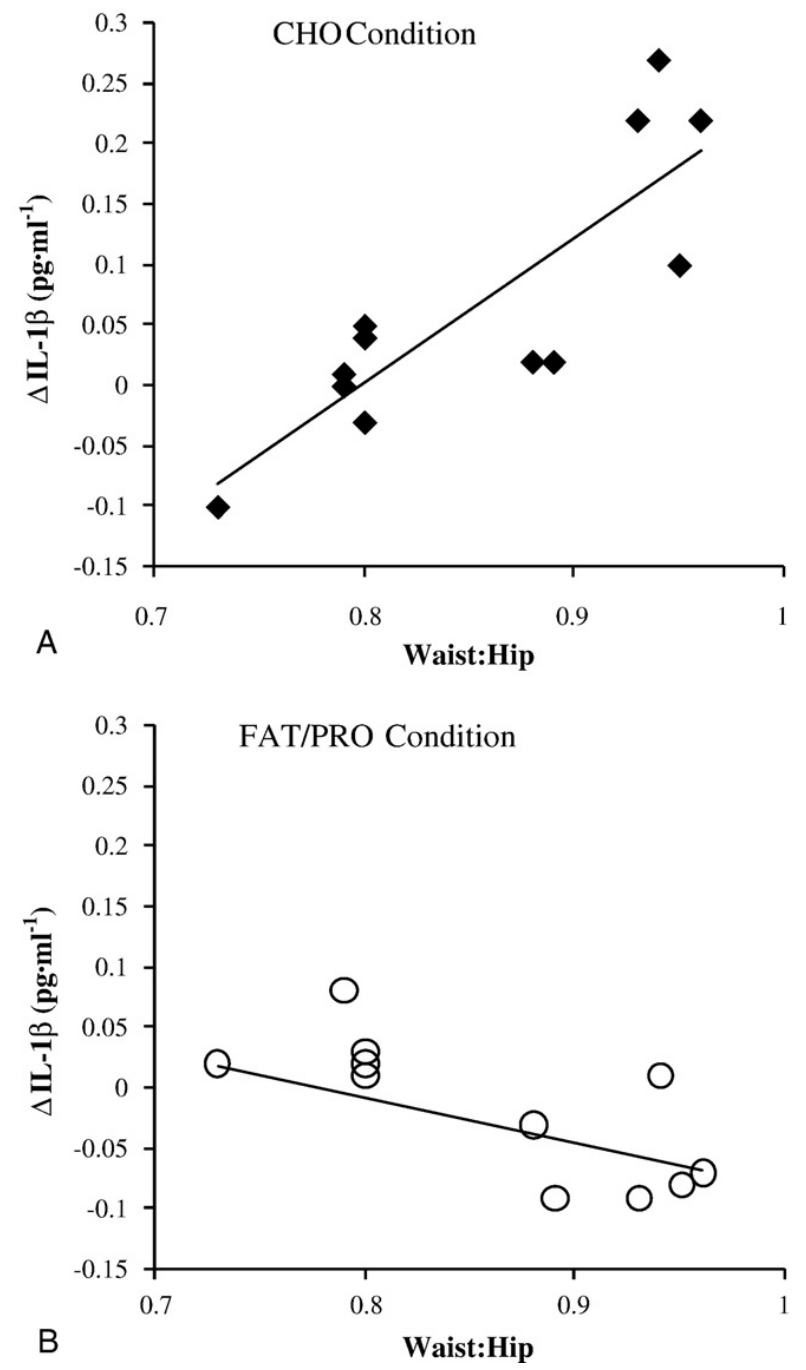

Fig. 3. Association of WHR with the change $(\Delta)$ in plasma IL-1 $\beta$ concentrations in the $\mathrm{CHO}(\mathrm{A})$ and FAT/PRO (B) conditions. Pearson product-moment correlations were $0.84(P<.05)$ and $-0.43(P>.05)$ in the $\mathrm{CHO}$ and FAT/PRO conditions, respectively.

The combination of an increase in fasting insulin along with no change in plasma glucose concentrations 23 hours postexercise may be an indication that the responsivity of $\beta$ cells and insulin resistance increased, according to the HOMA estimates of these parameters [21]. The positive association between these changes and WHR in the CHO condition may be an indication that the stress of this diet condition on $\beta$-cells was greater in those with greater central adiposity and vice versa for the FAT/PRO condition. Consistent with this macronutrient-specific influence on $\beta$ cell function, Krishnan et al [22] measured decreasing carbohydrate oxidation with increasing WHR and increasing lipid oxidation with increasing WHR after eccentric exercise. That is, we measured increased fasting insulin levels after the condition in which individuals' WHR predicted they would be less able to oxidize the predominant nutrient in their 
postexercise diet: after $\mathrm{CHO}$ intake in those with greater WHR and after FAT/PRO intake in those with lesser WHR. This relationship was stronger in the FAT/PRO condition than in the $\mathrm{CHO}$ condition.

Timing of the dietary manipulation in our study occurred from 0.5 to 8 hours postexercise so that the macronutrient differences would have the potential to influence early events in the postexercise inflammation response. Inflammatory neutrophil accumulation in human skeletal muscle has been measured as early as 45 minutes postexercise [23], and macrophage accumulation has been measured as early as 4 hours postexercise [24]. Increased TNF- $\alpha$, IL- 6 , and IL- 8 gene expression has been measured from 2 to 12 hours postexercise in muscle biopsies collected after resistance exercise [25]. At $1.45 \mathrm{~g}$ of carbohydrate per kilogram of body mass, carbohydrate intake ranged from 78.9 to $128.9 \mathrm{~g}$ of carbohydrate at each of the 3 meals in the $\mathrm{CHO}$ condition. Previous research studies report that intake of $75 \mathrm{~g}$ of glucose increased oxidative stress, oxygen free radical production by neutrophils and mononuclear leukocytes, activation of the proinflammatory transcription factor nuclear factor $-\kappa \mathrm{B}$, and gene expression of TNF- $\alpha$, IL- 6 , and other inflammation genes [26-28]. Thus, participants in the present investigation consumed enough carbohydrate to stimulate the inflammation process. However, consistent with our aim of having the experimental conditions reflect potential real-life conditions, the carbohydrate was consumed both in the form of food and with some fat and protein. In combination with the eccentric exercise, we found an increase in IL- $1 \beta$ but none of the other inflammation variables (TNF- $\alpha$, IL-6, sgp130, or CRP) in the CHO compared with the FAT/PRO condition. Either the $\mathrm{CHO}$ condition stimulated or the FAT/PRO condition inhibited the increase in IL- $1 \beta$ to produce the difference measured between conditions. Given the evidence of inflammation stimulation with glucose intake similar to the carbohydrate intake of the present investigation, we suggest that stimulation of inflammation was likely to have occurred.

Additional evidence to support our contention that there was a stimulation of inflammation in the $\mathrm{CHO}$ condition rather than inhibition of inflammation in the FAT/PRO condition is the potential for increased blood lipids actually to promote inflammation. At approximately $0.6 \mathrm{~g}$ of fat per kilogram of body weight, participants consumed 32.7 to 53.5 $\mathrm{g}$ of fat at each of the 3 meals. Stimulation of inflammation and insulin resistance has been measured after infusion of lipid emulsions and heparin to induce high free fatty acid concentrations $[6,11,29]$. However, consumption of fatty acids in the triglyceride form within food, as in the present investigation, is not likely to increase the plasma free fatty acid concentrations as dramatically as the lipid emulsion combined with heparin to activate lipoprotein lipase within the circulation. However, one limitation of the present study was that we were not able to measure plasma free fatty acid concentrations to reject this possibility.
The active, low-level inflammatory state that occurs with obesity and aging is increased under hyperglycemic conditions $[8,10]$. In the absence of an active inflammatory state in nonobese and/or young individuals, glycemic stresses have not increased inflammation. In fact, researchers have measured lower TNF- $\alpha$, IL- $1 \beta$, and IL- 6 production from lipopolysaccharide-stimulated mononuclear white blood cells collected during hyperglycemia in young, healthy men and women $[9,10]$. However, these researchers measured a positive association between waist circumference, fat mass, and visceral AT with TNF- $\alpha$ production. This suggests that there is a shift from an anti- to proinflammatory effect of hyperglycemia as BMI and WHR increase. We found a similar relationship with BMI and WHR and the magnitude of the plasma IL- $1 \beta$ and insulin responses in conjunction with eating high-carbohydrate foods after eccentric exercise to initiate a small inflammatory stimulus. Collectively, we infer from these findings that similar mechanisms likely to involve visceral AT associate with glycemic stress-induced inflammation in both obese and nonobese individuals. With respect to insulin resistance changes after eccentric exercise, our findings are not consistent with an earlier study by Krishnan et al [30] in which an inverse relationship was found between WHR and C-peptide (a relatively stable marker of insulin release) area under the curve during a hyperglycemic clamp 48 hours after eccentric exercise. The difference may be due to differences in the timing of the glycemic stress (0.5-8 vs $48-51$ hours postexercise) or in the timing of the insulin-related variable measurements ( 24 vs 48 hours).

The finding of increased fasting insulin and HOMA-IR 1 day after the exercise in the FAT/PRO condition was intriguing. This change occurred in the absence of measurable systemic inflammation, and we infer from this that the mechanism for the change in insulin may differ from that in the $\mathrm{CHO}$ condition. Inhibition of insulin signaling and $\beta$-cell function by increased intracellular and plasma fatty acid metabolites, including ceramides, has been demonstrated in several investigations [31-33]. This interference occurs within the time course of, and may play a role in, the changes in the present investigation. The inverse relationship between the change in insulin and both BMI and WHR is a novel finding and quite unique in that this is the first study that we know of to show greater susceptibility to insulin resistance changes in individuals with lower BMI and WHR. Visceral AT is less sensitive to inhibition of lipolysis by insulin, leading to a greater fatty acid flux $[15,34]$. Thus, individuals with a greater BMI and WHR may have been more accustomed to stress of increased fatty acid flux, which may have diminished the impact of the FAT/PRO diet on their $\beta$-cell responses. In contrast, there is a decrease in fatty acid oxidative capacity in insulin-resistant skeletal muscle [35], which might suggest that the FAT/PRO diet should have created metabolic stress that associated positively rather than negatively with BMI and WHR. Additional research is needed to understand why individuals with lower BMI and 
WHR responded to the FAT/PRO diet with an increase in their post-eccentric exercise insulin responses.

The amount of muscle damage in the present study was low relative to previous studies of eccentric exercise and insulin resistance, both in severity and affected muscle mass $[3,17,30]$. The changes in indirect markers of muscle damage are comparable to a previous study from our laboratory using a similar exercise model [36]. A variety of factors related to the exercise model in this study may account for the low muscle damage response including the subjective perception of maximal effort by the participants and the use and specific setup of our isokinetic dynamometer. We infer from our findings that a measurable change in plasma insulin and HOMA variable occurred with enough damage to induce a low level of strength loss for 24 hours or less and no increase in serum CK activity. As indicated, we chose this particular exercise regimen intentionally to have practical relevance to the types of stresses experienced by less active individuals. Asp et al [17] determined that the local effect of insulin resistance in the eccentrically exercised muscle accounted for only $8 \%$ of the total body change in insulin resistance. Modulation of whole-body insulin resistance by systemic inflammation, most notably TNF- $\alpha$, has been the hypothesized mechanism for insulin resistance after eccentric exercise [3,17]. This hypothesis is consistent with the findings in the $\mathrm{CHO}$ condition but not in the FAT/PRO condition. Either we did not detect the appropriate inflammation mediators in the FAT/PRO condition, or another mechanism exists under certain conditions. Those conditions are present in individuals with lower BMI and WHR in combination with a low-carbohydrate, high-fat, and high-protein dietary intake. Further investigation is needed to confirm this finding.

Although the amount of muscle damage induced in the present study was small, the loss of strength 24 hours postexercise for elbow flexion was greater in the $\mathrm{CHO}$ compared with the FAT/PRO condition. Whether this difference was induced by the inflammation that occurred in the $\mathrm{CHO}$ condition or occurred because of differences that occurred during the eccentric exercise cannot be determined conclusively. There was no difference in the amount of strength lost immediately postexercise between conditions. Furthermore, equal numbers of participants performed the $\mathrm{CHO}$ condition and FAT/PRO condition first; thus, the difference was not likely to be an order effect.

In conclusion, we measured increases in plasma insulin and related HOMA estimates of insulin resistance and $\beta$-cell responses after eccentric exercise. Consumption of highcarbohydrate foods elicited increases in insulin and inflammation that associated positively with BMI and WHR. Conversely, consumption of high-fat and high-protein foods elicited increases in insulin and inflammation that associated negatively with BMI and WHR in the same group of participants. Thus, both macronutrient intake and anthropometric difference had a major influence on the inflammation and HOMA estimates of insulin resistance and $\beta$-cell responses in younger, nonobese individuals. This is the first study that we know of to demonstrate these effects using nonclinical measures and readily available foods. With respect to insulin resistance, this is an important finding because a diet of the same macronutrient composition may have beneficial effects in one individual and harmful effects in another, for example, preventing a rise in insulin in one person and promoting a rise in insulin in another. Further research is needed to determine whether dietary recommendations for preventing insulin resistance should be adjusted according to BMI or WHR.

\section{Acknowledgment}

This study was funded by the Department of Health and Human Development at Montana State University and an ADVANCE Leadership grant from the National Science Foundation.

\section{References}

[1] Fernandez-Veledo S, Vila-Bedmar R, Nieto-Vazquez I, Lorenzo M. cJun $N$-terminal kinase $1 / 2$ activation by tumor necrosis factor-alpha induces insulin resistance in human visceral but not subcutaneous adipocytes: reversal by liver $\mathrm{X}$ receptor agonists. J Clin Endocrinol Metab 2009;94:3583-93.

[2] Tilg H, Moschen AR. Inflammatory mechanisms in the regulation of insulin resistance. Mol Med 2008:222-31.

[3] Del Aguila LF, Krishnan RK, Ulbrecht JS, Farrell PA, Correll PH, Lang $\mathrm{CH}$, et al. Muscle damage impairs insulin stimulation of IRS-1, PI 3-kinase, and Akt-kinase in human skeletal muscle. Am J Physiol Endocrinol Metab 2000;279:E206-12.

[4] Kahn SE. The relative contributions of insulin resistance and beta-cell dysfunction to the pathophysiology of type 2 diabetes. Diabetologia 2003;46:3-19.

[5] Krogh-Madsen R, Moller K, Dela F, Kronborg G, Jauffred S, Pedersen BK. Effect of hyperglycemia and hyperinsulinemia on the response of IL-6, TNF-alpha, and FFAs to low-dose endotoxemia in humans. Am J Physiol Endocrinol Metab 2004;286:E766-72.

[6] Krogh-Madsen R, Plomgaard P, Akerstrom T, Moller K, Schmitz O, Pedersen BK. Effect of short-term intralipid infusion on the immune response during low-dose endotoxemia in humans. Am J Physiol Endocrinol Metab 2008;294:E371-9.

[7] Clarkson PM, Litchfield P, Graves J, Kirwan J, Byrnes WC. Serum creatine kinase activity following forearm flexion isometric exercise. Eur J Appl Physiol Occup Physiol 1985;53:368-71.

[8] Gonzalez F, Minium J, Rote NS, Kirwan JP. Altered tumor necrosis factor alpha release from mononuclear cells of obese reproductive-age women during hyperglycemia. Metabolism 2006;55:271-6.

[9] Gonzalez F, Rote NS, Minium J, O’Leary VB, Kirwan JP. Obese reproductive-age women exhibit a proatherogenic inflammatory response during hyperglycemia. Obesity (Silver Spring) 2007;15: 2436-44.

[10] Kirwan JP, Krishnan RK, Weaver JA, Del Aguila LF, Evans WJ. Human aging is associated with altered TNF-alpha production during hyperglycemia and hyperinsulinemia. Am J Physiol Endocrinol Metab 2001;281:E1137-43.

[11] Solomon TP, Haus JM, Marchetti CM, Stanley WC, Kirwan JP. Effects of exercise training and diet on lipid kinetics during free fatty acid-induced insulin resistance in older obese humans with impaired glucose tolerance. Am J Physiol Endocrinol Metab 2009;297:E552-9. 
[12] Osborn O, Brownell SE, Sanchez-Alavez M, Salomon D, Gram H, Bartfai T. Treatment with an interleukin 1 beta antibody improves glycemic control in diet-induced obesity. Cytokine 2008;44:141-8.

[13] Shanmugam N, Reddy MA, Guha M, Natarajan R. High glucoseinduced expression of proinflammatory cytokine and chemokine genes in monocytic cells. Diabetes 2003;52:1256-64.

[14] Frayn KN, Summers LK, Fielding BA. Regulation of the plasma nonesterified fatty acid concentration in the postprandial state. Proc Nutr Soc 1997;56:713-21.

[15] Schenk S, Saberi M, Olefsky JM. Insulin sensitivity: modulation by nutrients and inflammation. J Clin Invest 2008;118:2992-3002.

[16] Rodriguez A, Catalan V, Gomez-Ambrosi J, Fruhbeck G. Visceral and subcutaneous adiposity: are both potential therapeutic targets for tackling the metabolic syndrome? Curr Pharm Des 2007;13:2169-75.

[17] Asp S, Daugaard JR, Kristiansen S, Kiens B, Richter EA. Eccentric exercise decreases maximal insulin action in humans: muscle and systemic effects. J Physiol 1996;494(Pt 3):891-8.

[18] Miles MP, Andring JM, Pearson SD, Gordon LK, Kasper C, Depner $\mathrm{CM}$, et al. Diurnal variation, response to eccentric exercise, and association of inflammatory mediators with muscle damage variables. J Appl Physiol 2008;104:451-8.

[19] Kirwan JP, del Aguila LF. Insulin signalling, exercise and cellular integrity. Biochem Soc Trans 2003;31(Pt 6):1281-5.

[20] Nosaka K, Clarkson PM, McGuiggin ME, Byrne JM. Time course of muscle adaptation after high force eccentric exercise. Eur J Appl Physiol Occup Physiol 1991;63:70-6.

[21] Wallace TM, Levy JC, Matthews DR. Use and abuse of HOMA modeling. Diabetes Care 2004;27:1487-95

[22] Krishnan RK, Evans WJ, Kirwan JP. Impaired substrate oxidation in healthy elderly men after eccentric exercise. J Appl Physiol 2003;94: 716-23.

[23] Fielding RA, Manfredi TJ, Ding W, Fiatarone MA, Evans WJ, Cannon JG. Acute phase response in exercise. III. Neutrophil and IL-1 beta accumulation in skeletal muscle. Am J Physiol 1993;265(1 Pt 2): R166-172.

[24] Beaton LJ, Tarnopolsky MA, Phillips SM. Contraction-induced muscle damage in humans following calcium channel blocker administration. J Physiol 2002;544(Pt 3):849-59.

[25] Louis E, Raue U, Yang Y, Jemiolo B, Trappe S. Time course of proteolytic, cytokine, and myostatin gene expression after acute exercise in human skeletal muscle. J Appl Physiol 2007;103:1744-51.
[26] Mohanty P, Hamouda W, Garg R, Aljada A, Ghanim H, Dandona P. Glucose challenge stimulates reactive oxygen species (ROS) generation by leucocytes. J Clin Endocrinol Metab 2000;85:2970-3.

[27] Dhindsa S, Tripathy D, Mohanty P, Ghanim H, Syed T, Aljada A, et al. Differential effects of glucose and alcohol on reactive oxygen species generation and intranuclear nuclear factor-kappaB in mononuclear cells. Metabolism 2004;53:330-4

[28] Aljada A, Ghanim H, Mohanty P, Syed T, Bandyopadhyay A, Dandona $\mathrm{P}$. Glucose intake induces an increase in activator protein 1 and early growth response 1 binding activities, in the expression of tissue factor and matrix metalloproteinase in mononuclear cells, and in plasma tissue factor and matrix metalloproteinase concentrations. Am J Clin Nutr 2004;80:51-7.

[29] Tripathy D, Mohanty P, Dhindsa S, Syed T, Ghanim H, Aljada A, et al. Elevation of free fatty acids induces inflammation and impairs vascular reactivity in healthy subjects. Diabetes 2003;52:2882-7.

[30] Krishnan RK, Hernandez JM, Williamson DL, O'Gorman DJ, Evans WJ, Kirwan JP. Age-related differences in the pancreatic beta-cell response to hyperglycemia after eccentric exercise. Am J Physiol 1998; 275(3 Pt 1):E463-70

[31] Itani SI, Ruderman NB, Schmieder F, Boden G. Lipid-induced insulin resistance in human muscle is associated with changes in diacylglycerol, protein kinase C, and IkappaB-alpha. Diabetes 2002;51: 2005-11

[32] Haus JM, Kashyap SR, Kasumov T, Zhang R, Kelly KR, Defronzo $\mathrm{RA}$, et al. Plasma ceramides are elevated in obese subjects with type 2 diabetes and correlate with the severity of insulin resistance. Diabetes 2009;58:337-43.

[33] Holland WL, Summers SA. Sphingolipids, insulin resistance, and metabolic disease: new insights from in vivo manipulation of sphingolipid metabolism. Endocr Rev 2008;29:381-402.

[34] Horowitz JF, Klein S. Whole body and abdominal lipolytic sensitivity to epinephrine is suppressed in upper body obese women. Am J Physiol Endocrinol Metab 2000;278:E1144-52.

[35] Kelley DE, Goodpaster B, Wing RR, Simoneau JA. Skeletal muscle fatty acid metabolism in association with insulin resistance, obesity, and weight loss. Am J Physiol 1999;277(6 Pt 1):E1130-41.

[36] Miles MP, Pearson SD, Andring JM, Kidd JR, Volpe SL. Effect of carbohydrate intake during recovery from eccentric exercise on interleukin-6 and muscle-damage markers. Int J Sport Nutr Exerc Metab 2007;17:507-20. 